\title{
Comparative Life Cycle Studies on Poly(3-hydroxybutyrate)-Based Composites as Potential Replacement for Conventional Petrochemical Plastics
}

\author{
Matteo Pietrini, ${ }^{\dagger}$ Lex Roes, ${ }^{\ddagger}$ Martin K. Patel, ${ }^{*}, \neq$ and Emo Chiellini*, ${ }^{\star}$ \\ Laboratory of Bioactive Polymeric Materials for Biomedical \& Environmental Applications, UdR-INSTM, \\ Department of Chemistry and Industrial Chemistry, University of Pisa, Via Risorgimento 35, 56126 Pisa, \\ Italy, and Copernicus Institute, Department of Science, Technology and Society, Utrecht University, \\ Heidelberglaan 2, 3584 CS Utrecht, the Netherlands
}

Received January 24, 2007; Revised Manuscript Received April 24, 2007

\begin{abstract}
A cradle-to-grave environmental life cycle assessment (LCA) of a few poly(3-hydroxybutyrate) (PHB) based composites has been performed and was compared to commodity petrochemical polymers. The end products studied are a cathode ray tube (CRT) monitor housing (conventionally produced from high-impact polystyrene, HIPS) and the internal panels of an average car (conventionally produced from glass-fibers-filled polypropylene, $\mathrm{PP}-\mathrm{GF}$ ). The environmental impact is evaluated on the basis of nonrenewable energy use (NREU) and global warming potential over a 100 years time horizon (GWP100). Sugar cane bagasse (SCB) and nanoscaled organophilic montmorillonite (OMMT) are used as PHB fillers. The results obtained show that, despite the unsatisfying mechanical properties of PHB composites, depending on the type of filler and on the product, it is possible to reach lower environmental impacts than by use of conventional petrochemical polymers. These savings are mainly related to the PHB production process, while there are no improvements related to composites preparation. SCBbased composites seem to be environmentally superior to clay-based ones.
\end{abstract}

\section{Introduction}

Replacing conventional petrochemical plastics with biobased and/or biodegradable ones is considered a key opportunity for developing a more sustainable use of materials. Petrochemical plastics are nowadays widely used for the production of consumer goods, mainly for their large availability, low cost, and easy processability on an industrial scale, but their effective biostability and fossil origin make them questionable from an environmental point of view. On the other hand, it is now commonly accepted that biodegradability is not a sufficient condition for the "eco-friendliness" of a polymeric product. Instead, it is necessary to take into account the environmental impact of all stages of product life, from raw materials extraction, to manufacture, to use, to end-product disposal.

As a result, in these last years, environmental life cycle assessment (LCA) studies have been published on the production of some of the most investigated biodegradable polymers, such as polyhydroxyalkanoates (PHAs) ${ }^{1,2}$ and polylactide (PLA NatureWorks), ${ }^{3}$ sometimes leading to quite contrary conclusions. ${ }^{4,5}$ It is well-known that biodegradable polymers produced from renewable resources tend to have relatively poor mechanical and thermal properties. In order to improve their performance, it is possible to use several techniques, like the formulation of blends with other polymers or additives or the preparation of composites in which the biodegradable polymer acts as a matrix. ${ }^{6-9}$

In the last 2 decades the preparation of composites has been one of the key topics in polymer science. In particular, two

* Corresponding authors. e-mail: emochie@dcci.unipi.it (E.C.) and m.k.patel@uu.nl (M.K.P.).

University of Pisa.

$\doteqdot$ Utrecht University. classes of composites seem to be very promising, namely nanocomposites and natural fibers composites. Nanocomposites are very appreciated because with a relatively small quantity of filler, commonly an organophilic modified clay, it is possible to improve several polymer properties, such as gas permeability and thermal and mechanical properties. ${ }^{10,11}$ On the other hand, composites filled with natural fibers (e.g., flax, cellulose whiskers, hemp, wood flour) offer good mechanical properties combined with low density and cost, in addition to the biodegradability of the filler. ${ }^{12,13}$ If also the polymer is biodegradable and of natural origin, this class of materials is identified as biocomposites. If the continuous polymer matrix is biodegradable but of synthetic origin, the respective composites with natural organic filler are identified as biobased composites.

Several studies have been performed in order to test the environmental performance of biobased and nanobased composites with respect to conventional polymers, especially in automotive, ${ }^{14-17}$ packaging, and transportation applications. ${ }^{18}$ These studies show clearly that the use of composites with both clays and natural fibers (like hemp, flax, or china reed fibers) can lead to considerable environmental benefits, if compared with conventional materials, like glass-fibers-filled polypropylene (PP-GF), acrylonitrile/butadiene/styrene copolymer (ABS), or steel. However, these studies take in account only the use of composites based on petrochemical and biostable polymers, but never a formulation with a biodegradable polymer as a matrix.

In the present work, we conducted a cradle-to-grave environmental LCA of a few poly(3-hydroxybutyrate) (PHB) based composites, with the purpose of assessing the potential environmental benefits that can be reached with the application of these new biodegradable materials instead of petrochemical polymers. The products investigated are cathode ray tube (CRT) monitor housing (conventionally made of high impact polysty- 


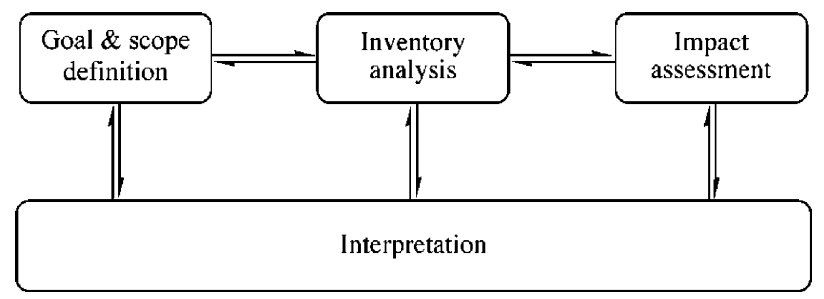

Figure 1. General phases of a life cycle assessment.

rene, HIPS) and the internal panels of an average car (conventionally made of $\mathrm{PP}-\mathrm{GF}$ ). $\mathrm{PHB}$ fillers are sugar cane bagasse (SCB) and organophilic montmorillonite (OMMT). This evaluation is performed considering two key environmental parameters, i.e., nonrenewable energy use (NREU) and global warming potential over a 100 years time horizon (GWP100).

LCA Fundamentals. As indicated in the ISO-14040 series, the life cycle assessment methodology distinguishes four phases: goal and scope definition, inventory analysis, impact assessment, and interpretation (Figure 1). ${ }^{19}$

Goal and Scope Definition. LCA application, type, reason, and audience are stated, together with the geographical and temporal scope. The system boundaries and functional unit (FU) are also determined.

Inventory Analysis (LCI). The process is modeled in a flow chart. The inputs (energy, materials) and the environmental releases of each process phase are determined, in relation to the functional unit.

Impact Assessment (LCIA). On the base of LCI, the environmental impacts related to the functional unit are determined. The results can be grouped and weighted.

Interpretation. The data obtained in previous steps of LCA are discussed and conclusions are drawn.

\section{Goal and Scope Definition}

The goal of this paper is to predict the environmental benefits that could be reached by the replacement of conventional petrochemical polymers with PHB-based composites. Our assessment is based on samples that were prepared and characterized in our laboratory at the University of Pisa. To this aim, two end products have been chosen: the housing of an average 17" CRT monitor for a desktop computer and the internal panels of an average car. Throughout the evaluation of the indicators NREU and GWP100, we tried to understand how each step of the LCA and material properties influence the final environmental performance of the end products.

In full-scale LCA studies, several impact categories are taken into account, among them eutrophication (EP), acidification (AP), ozone layer depletion (ODP), ecotoxicity (ETP), and human toxicity (HTP). ${ }^{20}$ In contrast, only two environmental indicators are considered in the present study, namely, NREU and GWP100. This choice is due to a general lack of data about the PHB production process, which is in an early stage of development, without large-scale facilities and publicly available measured results. While our environmental analysis is therefore bound to be incomplete, it can provide a useful first approximation of the environmental impacts given the findings of Huijbregts et al., ${ }^{21}$ according to which the use of NREU can be generally considered a reliable indicator of the environmental performances of products and processes. The relevance of our analysis is obvious in view of the plans of PHB Industrial SA (Brazil), which is analyzing the possibility to build a plant for PHA with a capacity of 10000 ton/year, ${ }^{22}$ and Metabolix (U.S.),
Table 1. Density and Young Modulus $(E)$ of PHB-Based Composites and Conventional Polymers

\begin{tabular}{lcclcc}
\hline & $\begin{array}{c}\text { density } \\
\left(\mathrm{t} / \mathrm{m}^{3}\right)\end{array}$ & $\begin{array}{c}E \\
(\mathrm{GPa})\end{array}$ & & $\begin{array}{c}\text { density } \\
\left(\mathrm{t} / \mathrm{m}^{3}\right)\end{array}$ & $\begin{array}{c}E \\
(\mathrm{GPa})\end{array}$ \\
\hline HIPS & 1.05 & 2.00 & PHB-10OMMT & 1.23 & 1.71 \\
PP-GF & 1.40 & 5.75 & PHB-10SCB & 1.15 & 1.69 \\
PHB-5OMMT & 1.22 & 1.48 & PHB-20SCB & 1.10 & 1.73 \\
\hline
\end{tabular}

which has announced plans to build the first commercial plant with an annual capacity of 50000 ton. ${ }^{23}$

Where needed, the impact of electricity production has been calculated using a weighed average of UCTE (74.4\%), NORDEL (15.1\%), and CENTREL (10.5\%) electricity, with a power generation efficiency of about $35 \% .^{24}$ This mix is representative for European electricity. The assumed petrochemical polymer production and processing technologies are representative for today's industrial facilities in Europe.

Functional Units. As functional units we chose the following.

CRT monitor housing: one housing of an average 17" CRT monitor for a desktop computer; the conventional housing is assumed to be made of HIPS, with a weight of $2.2 \mathrm{~kg} .{ }^{25}$

Internal car panels: the total of all internal panels of one average car with a life time of 10 years and a total distance traveled of $150000 \mathrm{~km}$. According to the European Association of Plastics Manufacturers (PlasticsEurope) the total weight of an average car is $1130 \mathrm{~kg}$ and the weight of the conventional internal panels is $20 \mathrm{~kg}$; $^{26}$ the composition of the panels is assumed to be 63 wt \% PP, 30 wt \% glass fibers (GF), and 7 wt \% maleic anhydride grafted polypropylene (MAPP) as compatibilizer between PP and GF.

Preparation and Properties of PHB Composites. The melt blending process of PHB-based composites has been carried out in a torque rheometer at $170{ }^{\circ} \mathrm{C}$ and $30 \mathrm{rpm}$ for $7 \mathrm{~min} .{ }^{27}$ SCB (10 and $20 \mathrm{wt} \%$, no surface treatment) and OMMT (5 and $10 \mathrm{wt} \%$, treated with a silane modifier) have been used as filler materials. X-ray diffraction plots (not reported here) showed a possible intercalation of the clays inside the PHB matrix. No compatibilizers between PHB and fillers have been used. A more detailed discussion about composites preparation and characterization will be provided in forthcoming papers. ${ }^{28,29}$ During the tensile measurements, 12 specimens of each composite have been tested. The values for the density and the Young modulus of the PHB-based composites and the conventional materials considered in this study are listed in Table 1. In the case of conventional plastics (HIPS and PP-GF) these values have been evaluated from commercially available products. ${ }^{30}$

Weight of PHB-Based End Products. Starting from engineering pronciples, Ashby developed a generic approach in order to determine the performance of a material in a given function. ${ }^{31}$ Combining the functional requirements, the geometry and the properties of the material, this approach aims at indicating which property has to be improved in order to maximize the performance of the material in the application. Ashby calls his indicator for the property (or the property group) of a material the material index (MI). The larger the value for MI is, the better the mechanical properties of the product under consideration are. The MI formula that represents best the performance features of the products studied in the present work is the one derived for a stiffness-limited panel with specified width and length and free thickness. As indicated in eq 1, the MI for these constraints is defined as

$$
\mathrm{MI}=E^{1 / 3} / \rho
$$


Table 2. Estimated Change of Weight of PHB-Based Composites Compared to Conventional Polymers

\begin{tabular}{lccccc}
\hline & $\begin{array}{c}\text { CRT } \\
\text { housing } \\
\text { (wt \%) }\end{array}$ & $\begin{array}{c}\text { car } \\
\text { panels } \\
\text { (wt \%) }\end{array}$ & composite & $\begin{array}{c}\text { CRT } \\
\text { housing } \\
\text { (wt \%) }\end{array}$ & $\begin{array}{c}\text { car } \\
\text { panels } \\
\text { (wt \%) }\end{array}$ \\
\hline PHB-5OMMT & +27.9 & +36.3 & PHB-10SCB & +15.9 & +23.5 \\
PHB-10OMMT & +23.4 & +31.5 & PHB-20SCB & +9.9 & +17.1 \\
\hline
\end{tabular}

where $E$ is the Young modulus and $\rho$ is the density of the material (Table 1). The larger the value of MI is, the less material that is required to fulfill the function studied. A high value for $\mathrm{MI}$ is the consequence of a large Young modulus $E$ or a low density $\rho$ or both. By applying the MI to two materials with different properties (e.g., a conventional versus a new, innovative material), it is possible to calculate the weight difference between the two end products that have the same functionality, as shown in eq 2

$$
\text { change of weight }(\%)=100\left[\left(\mathrm{MI}_{\text {conv }} / \mathrm{MI}_{\text {new }}\right)-1\right]
$$

where $\mathrm{MI}_{\text {conv }}$ and $\mathrm{MI}_{\text {new }}$ are respectively the material indexes for the conventional and for the new material. The change of weight values of PHB-based composites calculated according to eq 2 for both options are reported in Table 2.

All the PHB-based composites are calculated to weigh more than the conventional materials. This increment ranges from approximately $10 \%$ for $\mathrm{PHB}-20 \mathrm{SCB}$ in the case of the monitor housing to $36 \%$ for the internal car panels for PHB-5OMMT. As shown in Table 1, all PHB-based composites show a lower Young modulus compared to conventional materials. In particular, the modulus of the PP-GF composite is 3.3-3.9 times larger than the modulus of the PHB composites. In addition, polyhydroxyalkanoates have a high density, which is also to their disadvantage. Therefore, despite the relatively high density of PP-GF $\left(1.40 \mathrm{t} / \mathrm{m}^{3}\right.$ as compared to $1.22-1.10 \mathrm{t} / \mathrm{m}^{3}$ for the PHB composites), the MI of this material $\left[1.28 \mathrm{GPa}^{1 / 3} /\left(\mathrm{t} / \mathrm{m}^{3}\right)\right]$ is still the highest one among all the polymers considered. For comparison, the MI of PHB-based composites ranges from 0.94 $\mathrm{GPa}^{1 / 3} /\left(\mathrm{t} / \mathrm{m}^{3}\right)$ for $\mathrm{PHB}-5 \mathrm{OMMT}$ to $1.09 \mathrm{GPa}^{1 / 3} /\left(\mathrm{t} / \mathrm{m}^{3}\right)$ for $\mathrm{PHB}-$ 20SCB. The weight reduction effect of SCB fibers on the PHB composites density is therefore neutralized by the relatively low Young modulus observed during the tensile mechanical testing.

System Boundaries. A simplified flow chart describing the production of the CRT monitor housing and the internal car panels is shown in Figure 2. Both the end products are assumed to be produced by injection molding, which is the conventional technique used in the preparation of these products. In the case of composite materials (PHB-OMMT, $\mathrm{PHB}-\mathrm{SCB}$, and $\mathrm{PP}-$ $\mathrm{GF})$, before injection molding, there is an extrusion process, which is needed for mixing and homogenization of the various components. HIPS is not extruded before injection molding because it is used as pure polymer.

OMMT production includes clay extraction, ion exchange, hydrocycloning, spray drying, organic modification, filter pressing, heating, and milling. A more detailed description of this process can be found in work by Roes et al. ${ }^{32}$

The data used for the PHB production process originate from the BREW project. ${ }^{33}$ Being cradle-to-factory gate data, the values include agricultural cultivation and sugar production, the bioprocess (polymer production by fermentation), and downstream processing. The sugar needed to feed the microorganisms is extracted from sugar cane (PHB1 case) and corn starch (PHB2 case). The residual biomass produced along with the sugar is considered to be combusted for electricity production, with an assumed power generation efficiency of about 35\%. In the case of sugar cane, a small part of the residual biomass is the SCB used as PHB filler. Only $1-3 \%$ of SCB produced during sugar cane milling is used for this purpose, depending on the composition of the composite.

$\mathrm{PP}-\mathrm{GF}$ formulation is assumed to contain MAPP in order to improve the adhesion between PP and the fillers. MAPP is produced by extruding PP and maleic anhydride in the presence of a peroxidic agent.

In our environmental assessment, the use phase of internal car panels is represented by the fuel consumption of the car, which is influenced by the weight of the panels. In contrast, the environmental impacts of the CRT monitor during the use phase can be neglected.

After their useful life, we assume for both products postconsumer waste management by municipal solid waste incineration with energy recovery. The NREU for transport and waste treatment has been considered $1 \%$ of NREU of polymers production. The GWP100 impacts have been calculated by assuming that all the carbon fixed in the petrochemical polymers is converted to carbon dioxide during the combustion process. In the case of $\mathrm{PHB}$ and $\mathrm{SCB}$ (produced from renewable resources), this contribution has not been calculated because the $\mathrm{CO}_{2}$ originating from the incineration of the composites was extracted from the atmosphere during plant growth, thus forming a closed cycle (under the assumption of plant regrowth).

In order to reflect energy recovery during incineration of the composites after their useful life, credits are introduced in the calculation. We assume that for each joule of incinerated waste there is a credit of $0.12 \mathrm{~J}$ of electricity and $0.12 \mathrm{~J}$ of heat. ${ }^{34}$ The energy and carbon dioxide bonus coming from the incineration has been calculated on the basis of the calorific value of the polymers and SCB (which is the only organic filler) and has then been deducted as credits from the total (gross) NREU and GWP100 impacts. Being inorganic materials, GF and OMMT are assumed to be neutral with regard to energy and greenhouse gases (GHG) emissions in the waste incineration end stage.

\section{Inventory Analysis}

The inventory analysis is based on the flow chart reported in Figure 2. The data sources for each process phase are summarized in Table 3. As mentioned above, the sugar used for the PHB fermentation process is produced from sugar cane (PHB1 case) or from corn starch (PHB2 case). ${ }^{33}$ The biomass that is left over from these processes is assumed to be combusted for the production of electricity. This replaces the use of fossil fuels (e.g., coal and natural gas), leading to potentially substantial environmental credits. In the case of sugar cane, large amounts of biomass (the so-called bagasse) can be used for power generation. This is the reason for the negative values calculated for the final impacts of PHB production in the PHB1 case $(-22.7 \mathrm{GJ} / \mathrm{t}$ and $-3100 \mathrm{~kg} \mathrm{CO} 2$ equiv/t for NREU and GWP100, respectively). The lower quantity of biomass available in corn starch offers relatively small savings, making this production less favorable from an environmental point of view $(\mathrm{NREU}=38.6 \mathrm{GJ} / \mathrm{t}$ and $\mathrm{GWP} 100=0 \mathrm{~kg} \mathrm{CO} 2$ equiv/t).

For injection molding, data published by PlasticsEurope have been used. ${ }^{39}$ According to PlasticsEurope the NREU for PP production and injection molded PP are 73.0 GJ/t and 113.2 $\mathrm{GJ} / \mathrm{t}$ respectively (the first value refers to the system from "cradle" to PP pellets, while the second value represents the system from "cradle" to the injection molded compound). For injection molding, PlasticsEurope reports a substantial amount of natural gas (almost $12 \%$ of the total gross energy use) to be 


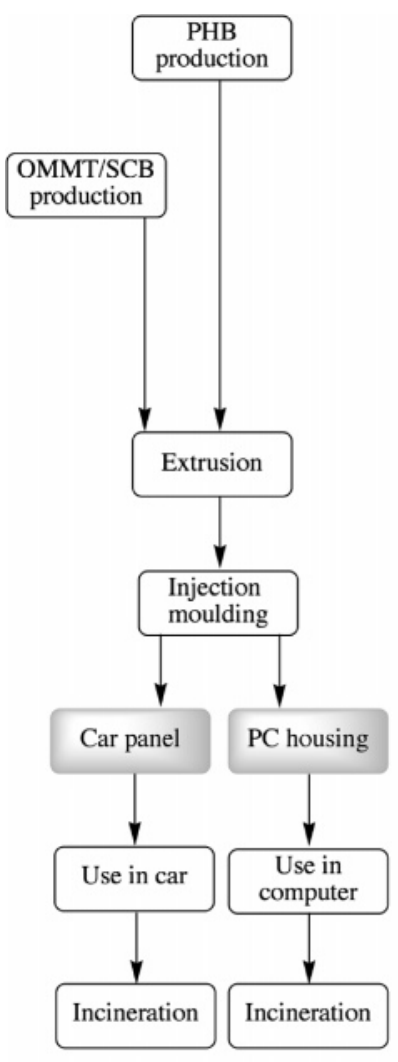

(a)

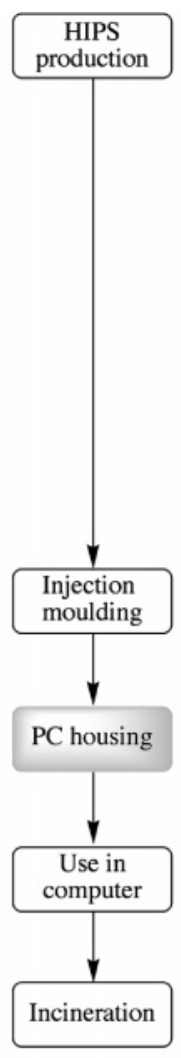

(b)

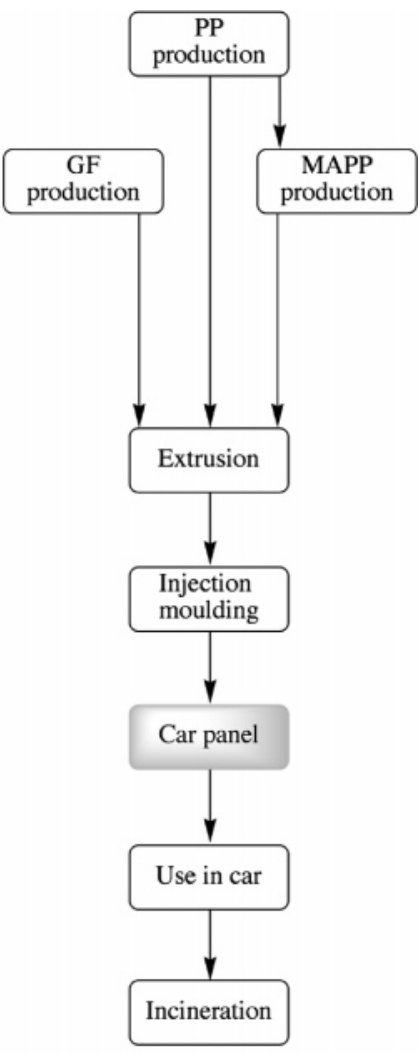

(c)

Figure 2. Simplified flow chart for the production process of both functional units: PHB-based composites CRT monitor housing and internal car panels (a), HIPS CRT monitor housing (b), and PP-GF internal car panels (c).

Table 3. Data Sources for Each LCA Stage

\begin{tabular}{lc}
\hline \multicolumn{1}{c}{ fillers production } & data source \\
\hline $\begin{array}{l}\text { OMMT } \\
\text { SCB }\end{array}$ & $\begin{array}{l}\text { our calculation } \\
\text { ref } 35\end{array}$ \\
& $\begin{array}{c}\text { our calculation } \\
\text { based on ref } 36\end{array}$ \\
\hline \multicolumn{1}{c}{ polymers production } & data source \\
\hline PHB1 & ref 33 \\
PHB2 & ref 33 \\
PP & ref 37 \\
MAPP & our calculation \\
HIPS & ref 38 \\
\hline processing and use phase & data source \\
\hline extrusion & our calculation ${ }^{32}$ \\
injection molding & estimation based \\
diesel use phase & on ref 39 \\
incineration and energy recovery & ref 40 \\
\hline polymer and composites & our calculation based \\
incineration & on CO ${ }_{2}$ content \\
energy recovery & our calculation based \\
& on calorific content \\
\hline
\end{tabular}

used only for space heating. For the calculations presented in this paper, we excluded natural gas use for space heating, thereby arriving at lower values $(25 \mathrm{GJ} / \mathrm{t}$ and $1220 \mathrm{~kg} \mathrm{CO}$ equiv/t for NREU and GWP100, respectively), which are in good agreement with other publications. ${ }^{41,42}$
Table 4. Data Used in the Calculation of the Use Phase for Internal Car Panels

\begin{tabular}{lccc}
\hline \multicolumn{1}{c}{ composite } & $\begin{array}{c}\text { panels } \\
\text { weight } \\
(\mathrm{kg})\end{array}$ & $\begin{array}{c}\text { car fuel } \\
\text { economy } \\
(\mathrm{km} / \mathrm{kg})\end{array}$ & $\begin{array}{c}\text { panels } \\
\text { fuel use } \\
(\mathrm{kg})\end{array}$ \\
\hline PP-GF & 20.0 & 15.13 & 115.2 \\
PHB-5OMMT & 27.3 & 15.07 & 156.9 \\
PHB-10OMMT & 26.3 & 15.07 & 151.4 \\
PHB-10SCB & 24.7 & 15.09 & 142.2 \\
PHB-20SCB & 23.4 & 15.10 & 134.8 \\
\hline
\end{tabular}

${ }^{a}$ During car lifetime.

During the use phase of the car, the share fuel that can be assigned to the weight of internal car panels has been calculated with the following assumptions. The weight of the car without the panels is $1222 \mathrm{~kg}$. This value has to be allocated between the car $(1110 \mathrm{~kg})$ and the passengers $(112 \mathrm{~kg})$. The weight of the passengers has been derived from an average of 1.6 passengers of $70 \mathrm{~kg}$ each. The distance driven throughout the life of the car is $150000 \mathrm{~km}$. For $1 \mathrm{~km}$ driven, $0.0125 \mathrm{~kg}$ of diesel and $0.0536 \mathrm{~kg}$ of petrol are combusted. ${ }^{40}$ The dependence of fuel use on the weight of the car containing the PHB-based panels has been calculated according eq 3 :

$$
\mathrm{FC}_{\text {new }}=\mathrm{FC}_{\text {conv }}\left(W_{\text {conv }} / W_{\text {new }}\right)^{0.72}
$$

where $\mathrm{FC}_{\text {conv }}$ and $W_{\text {conv }}$ are respectively the fuel consumption and the weight of the car with the conventional panels and $\mathrm{FC}_{\text {new }}$ and $W_{\text {new }}$ are respectively the fuel consumption and the weight of the car with the new panels. ${ }^{14}$ Similarly, the same equation has been used in order to evaluate the fraction of fuel to be assigned to the panels. The specific weight of diesel is 0.84 
Table 5. Estimation of NREU and GWP100 for the Cradle-to-Grave System of Conventional and PHB-Based CRT Monitor Housings and Internal Car Panels

\begin{tabular}{|c|c|c|c|c|}
\hline & \multicolumn{2}{|c|}{ CRT housing } & \multicolumn{2}{|c|}{ internal car panels } \\
\hline & $\begin{array}{c}\text { NREU } \\
\text { (MJ/FU) }\end{array}$ & $\begin{array}{c}\text { GWP100 } \\
\text { (kg CO } \\
\text { equiv/FU) }\end{array}$ & $\begin{array}{c}\text { NREU } \\
\text { (GJ/FU) }\end{array}$ & $\begin{array}{c}\text { GWP100 } \\
(\mathrm{kg} \mathrm{CO} 2 \\
\text { equiv/FU) }\end{array}$ \\
\hline HIPS & 200.0 & 15.1 & - & - \\
\hline PP-GF & - & - & s 8.2 & s 569.9 \\
\hline PHB1-5OMMT & 8.9 & 0.5 & 9.0 & 642.5 \\
\hline PHB1-10OMMT & 22.9 & 1.3 & 8.8 & 627.2 \\
\hline PHB1-10SCB & 1.3 & 0.1 & 8.1 & 578.8 \\
\hline PHB1-20SCB & 6.8 & 0.5 & 7.7 & 552.1 \\
\hline PHB2-5OMMT & 171.0 & 8.7 & 10.6 & 722.8 \\
\hline PHB2-100MMT & 171.1 & 8.8 & 10.3 & 700.6 \\
\hline PHB2-10SCB & 140.4 & 7.2 & 9.5 & 647.7 \\
\hline PHB2-20SCB & 124.8 & 6.4 & 8.9 & 610.2 \\
\hline
\end{tabular}

$\mathrm{kg} / \mathrm{L} .{ }^{43}$ The results of this calculation, which are listed in Table 4 show that, as expected, the fuel economy of the car, in terms of kilometer driven per kilogram of fuel, decreases with increasing weight of panels. Concerning the fuel use attributed to the panels, the best result is observed for the PHB-20SCB case (around $17 \%$ more than $\mathrm{PP}-\mathrm{GF}$ panels), which represents the lightest PHB-based product.

\section{Impact Assessment}

In Table 5 NREU and GWP100 impacts for both products studied are listed. The same results are visualized in Figures 3 and 4 as relative impacts, compared with the impacts of conventional products.

In the case of the CRT monitor housing (Figure 3), all the PHB-based composites score better when compared to their conventional counterpart made of HIPS. Both indicators are substantially lower both for PHB produced from sugar cane (PHB1) and PHB derived from corn starch (PHB2). In particular, the PHB1 case shows very low values, as a consequence of the particularly low environmental impacts for this polymer production process. Best savings are observed for PHB1-10SCB composite. This sample shows a reduction for both indicators by about $99 \%$ with respect to conventional HIPS housing. If compared with $\mathrm{PHB}-\mathrm{OMMT}$ samples, $\mathrm{PHB}-\mathrm{SCB}$ composites show even better savings.

A very different picture is found for internal car panels (Figure 4). On the one hand, similarly to the case of CRT monitor housing, best results are found for PHB produced from sugar cane (PHB1). On the other hand, even PHB1-based composites do not show relevant environmental savings for both indicators if compared with the conventional PP-GF panels. The only composite showing a lower impact for both indicators is PHB120SCB, with a reduction of around 5\% and 3\% for NREU and GWP100, respectively. However, these savings are too small to state their significance.

\section{Interpretation}

General Considerations. Since the late 1970s, PHAs have attracted the attention of many scientists because of their favorable environmental performances. Their renewable resources origin and biodegradability make this class of polymers very attractive for replacing conventional petrochemical polymers. ${ }^{44}$ However, the diffusion of PHAs on an industrial scale has been hampered for various reasons, like the high production cost, the difficulties in PHAs processing, and the unsatisfactory mechanical properties. In particular, PHB, which is the most common and studied PHA, is a highly crystalline brittle material, with a narrow processability window, due to the high thermal degradation rate during melt processing. These problems can be partially avoided by various strategies, like the internal plasticization of PHB (achieved by the copolymerization of PHB with others monomeric PHA units during the fermentation process) or the addition in the formulation of some commercial components like plasticizers or nucleating agents. By applying these techniques with a proper setting in processing parameters, PHB can be extruded or injection molded as a classic thermoplastic polymer. ${ }^{45,46}$ In the present work, no plasticizers or nucleating agents were added to the formulations. The composites were not extruded and injection molded but mixed using a discontinuous process and they were then compression molded. For the evaluation of the Young modulus, this procedure can be considered as reliable.

In order to estimate the weight of the new PHB-based end products, we used the MI for a stiff panel for both applications. However, it should be considered that this MI takes into account only the Young modulus and the density of the material while for the applications studied also other properties can play a very important role in the evaluation of the real applicability of the material, e.g., the impact resistance. As mentioned earlier, PHB is a brittle material, with a typical Izod impact value that is comparable with that of PP but 2-3 times lower than that of HIPS. ${ }^{30,44,47}$ So, if this parameter were also taken into account in the MI, this could change the results quite considerably. In principle, several approaches could be followed in order to obtain a more realistic MI: it would be also possible to try to derive another MI reflecting the impact resistance instead of Young modulus and then to combine the two indices or to consider them separately and choose the worst case. While further research would be required on this point, we chose a simple approach by only considering eq 1 for the time being.

As mentioned above, in the present study, the only two environmental indicators considered are NREU and GWP100. Usually the production of materials from natural resources requires a relatively small amount of fossil energy, because the main contribution comes from the solar energy. As a consequence, also GWP emissions are lower if compared with materials coming from nonrenewable resources. ${ }^{48}$ On the other hand, while in this case the values for the indicators NREU and GWP can be expected to be low, the score of other categories could be greatly affected by the cultivation of the renewable resources and complicated processes, possibly involving toxic compounds. Fertilizers, herbicides, and pesticides, needed for the cultivation of sugar cane and corn, can release in the environment a considerable amount of phosphates and nitrates, increasing the final score in HTP, ETP, and EP indicators. ${ }^{18}$ In the case of OMMT-based composites, also the potential release of free nanoparticles should be taken in account. The release may take place when manufacturing clay and composites or in the biodegradation stage, affecting mainly the score of ETP and HTP indicators. In this paper, we only mention these aspects, while focusing on NREU and GWP100 as environmental indicators.

Another very important aspect is represented by the feasibility of using biodegradable materials for durable products. The lifetime of products such as monitor housings or car panels is expected to be on the order of some years. In this view, it is of fundamental importance that the biodegradation of the product 


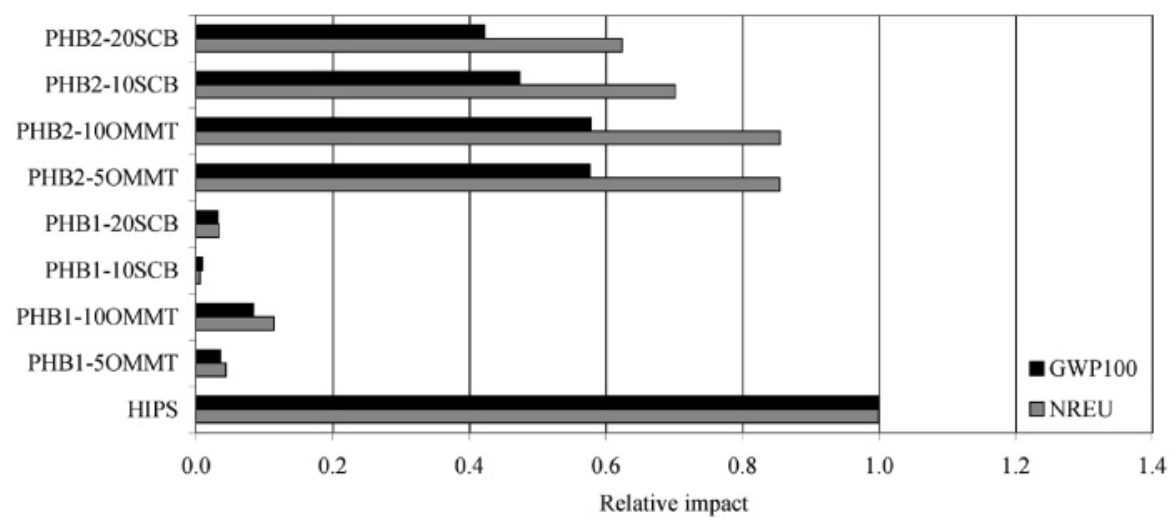

Figure 3. Relative NREU and GWP100 of CRT monitor housing for the system cradle-to-grave.

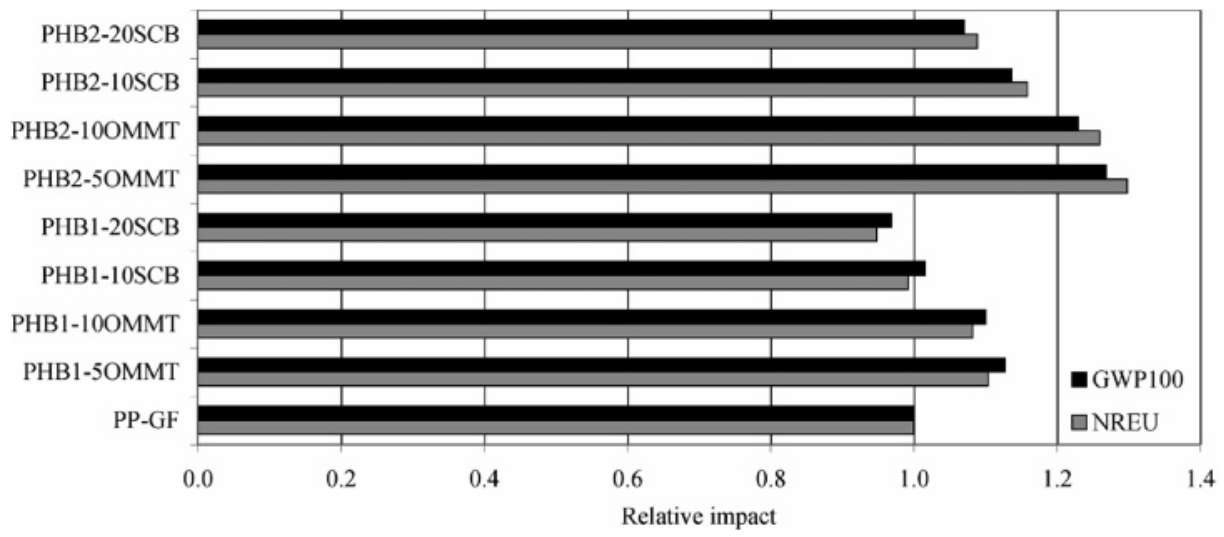

Figure 4. Relative NREU and GWP100 of internal car panels for the system cradle-to-grave.

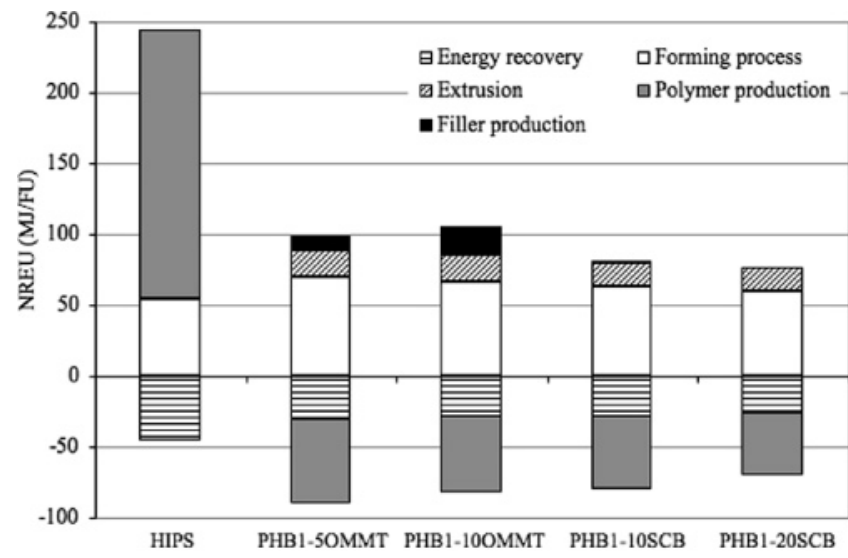

Figure 5. Contribution of each production stage to CRT monitor housing NREU for the PHB1 case.

does not take place during this useful period. In fact, it is wellknown that, during biodegradation process, the mechanical performances of a polymer decrease dramatically. Avella et al. found that the Young modulus of poly(3-hydroxybutyrate-co3-hydroxyvalerate) (PHBV), as well as PHBV-based composites reinforced with wheat straw fibers, decreased by around $20-$ $23 \%$ after a $15 \%$ weight loss due to biodegradation. ${ }^{49}$ However, it should be underlined that experimental biodegradation tests are usually performed in controlled and accelerated environments, such as immersion in bioactive soil or mature compost, and specific conditions of temperature, $\mathrm{pH}$, and moisture. Despite the use of monitor housings and car panels not taking place under such conditions, with a theoretical increase of the useful life of the products, there are some environmental factors (e.g., the prolonged exposition to heating due to the proximity of overheated mechanical and electrical components) that potentially could affect the substantial biostability of the products during their use. In this view, we can conclude that an accurate investigation concerning the effective durability of the PHB-based products under the conditions of use should be critically performed prior to any possible employment.

Life Cycle Interpretation. In Figure 5 we report for CRT monitor housing made of PHB1 the contribution of each production stage to NREU.

For HIPS, which is the conventional material, the total NREU is $200 \mathrm{MJ} /$ housing $(244 \mathrm{MJ} /$ housing without the energy credit from waste incineration). As mentioned above, the NREU associated with PHB production is $-22.7 \mathrm{GJ} / \mathrm{t}$ for $\mathrm{PHB}$ produced from sugar cane (PHB1) and $38.6 \mathrm{GJ} / \mathrm{t}$ for PHB produced from corn starch (PHB2). For PHB-based composites, the contribution of injection molding is higher than for HIPS (from 60 to 70 $\mathrm{MJ} /$ housing against $54 \mathrm{MJ} /$ housing for HIPS) because of the higher weight of the PHB-based monitor housing. In addition, we have also to account for the contribution of extrusion (needed for the preparation and homogenization of the composites) and the production of the filler, which are not needed in HIPS housing preparation. OMMT production represents about the $10 \%$ of the positive contribution for PHB1-5OMMT and around $19 \%$ for PHB1-10OMMT. The contribution of SCB production is basically negligible, because of the typically very low NREU needed for renewable resources. The energy credit from postconsumer waste incineration is higher for HIPS (44 $\mathrm{MJ} /$ housing) compared to PHB composites (from 26 to $30 \mathrm{MJ} /$ housing) because of the higher calorific content of HIPS (this is not compensated by the higher weight of the compounds made of PHB). The use phase for this end product has no contribution, because the electricity use of the monitor does not depend on the weight, the shape, or the material of the housing. These properties could influence the transportation of the monitors (to and from retail and to waste management), but this parameter 


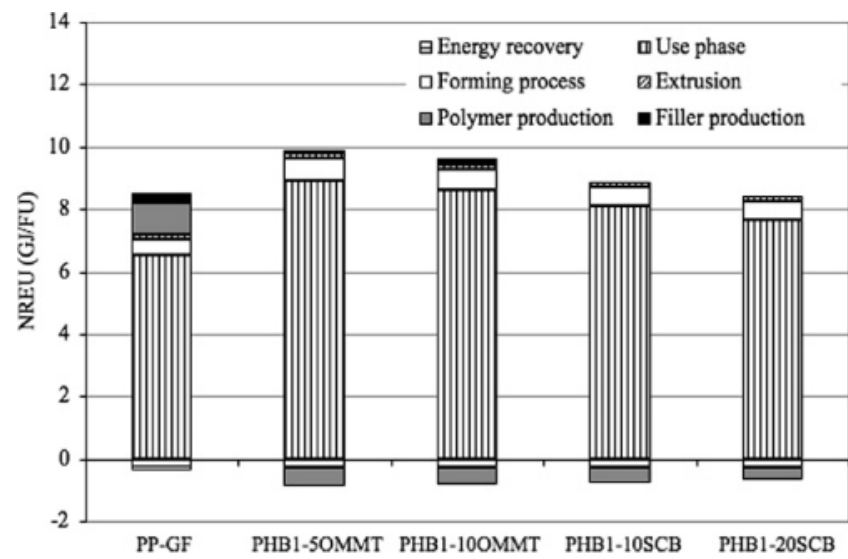

Figure 6. Contribution of each production stage to internal car panels NREU for the PHB1 case.

has not been included in the calculation because it is typically negligible. In conclusion, the life cycle stage that makes PHB composites so environmentally competitive is the PHB production. For the HIPS monitor housing, polymer production accounts for $190 \mathrm{MJ} /$ housing, which represents about $80 \%$ of the total positive contribution to NREU. In contrast, the NREU for the production of PHB1 (PHB coming from sugar cane) is negative, i.e., due to the large credits its production is a net source of NREU (instead of being a sink of NREU). As a consequence, $\mathrm{PHB} 1$ production decreases the overall NREU by around $43 \mathrm{MJ} /$ housing (PHB1-20SCB composite) to $60 \mathrm{MJ} /$ housing (PHB1-5OMMT). This range is caused by the different amount of PHB required for the various cases.

In the case of the internal car panels, the results are very different (Figure 6). The main difference compared to the display housing is the large contribution of the use phase in the case of the car panels. If we had prepared the LCA for the car panels for the system "cradle-to-factory gate" (instead of cradle-tograve) the results would have been very similar to the display housing.

For the system cradle-to-factory gate, the NREU of PHBbased internal car panels represents only approximately $15 \%$ (PHB1-10SCB) to 26\% (PHB1-10OMMT) of the NREU value of PP-GF. But if the use phase is included, the NREU of the end products from PHB composites score much worse than the product made from conventional polymer. The reason is the higher weight of the composites, which leads to higher fuel consumption. While for a CRT monitor the housing does not have any influence on the electricity consumption of the monitor, the diesel consumption of the car is related to the weight of the internal panels. Not considering the energy recovery from incineration, which is anyway bigger for PPGF because of the higher calorific value of PP, the contribution of the service phase for $\mathrm{PP}-\mathrm{GF}$ represents $84 \%$ of the total positive part. In $\mathrm{PHB}$, this contribution represents basically $100 \%$ of the total impact. This means that the bad mechanical properties of the composites, which led to an increase in component weight, overcompensate all the savings provided by the environmentally favorable $\mathrm{PHB}$ production process. Analogous considerations can be made with regard to GWP100 emissions relative to this product.

Sensitivity Analysis on Internal Car Panels. In Figure 7 we report the relation between the relative NREU and the Young modulus of PHB-based composites for internal car panels in the PHB1 case. The relative NREU represents the ratio between NREU of PHB-based composites and the NREU of PP-GF. The trend is exponential because of the assumed formula for

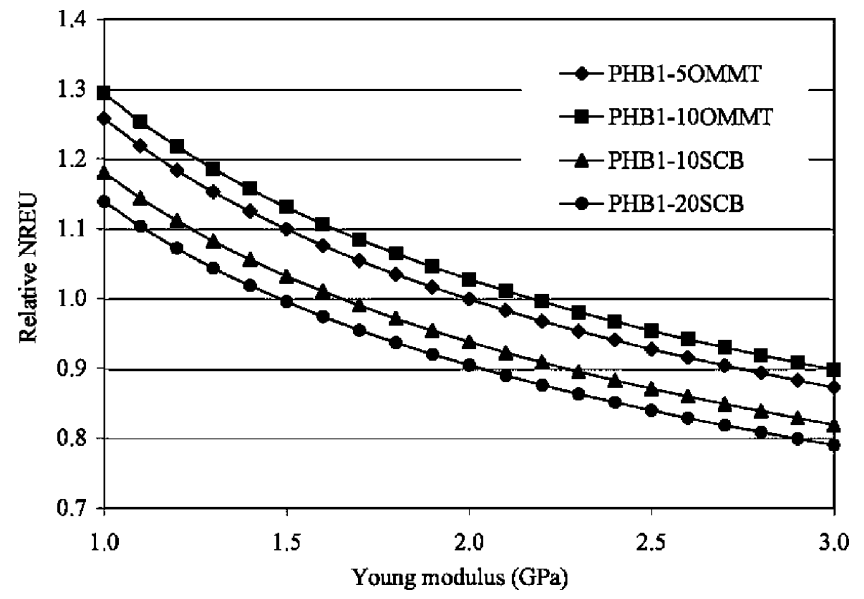

Figure 7. Relation between relative NREU and Young modulus of PHB-based composites for internal car panels for the PHB1 case for the system cradle-to-grave.

the MI (eq 1), according to which the Young modulus is elevated at the power of $1 / 3$. It is clear that the final NREU is strongly affected by the value of the Young modulus. This property is related to the final weight of the car panels and, consequently, to the use phase, which, as discussed above, contributes most to the final NREU of this end product.

According to our calculations for the PHB1 case, the Young modulus of $\mathrm{PHB}-\mathrm{OMMT}$ composites should reach at least values of around 2.0 $\mathrm{GPa}$ (PHB1-5OMMT) and $2.2 \mathrm{GPa}$ (PHB1-10OMMT) in order to make these materials attractive from an environmental point of view.

Several techniques can be used in order to improve the mechanical properties of polymeric composites, like the use of optimized coupling agents between the polymer and the filler, the surface treatment of the filler itself, or increasing the filler percentage in the composite. Attempts should be made to improve these techniques further with the goal of reaching the target values just mentioned.

For PHB-OMMT composites, we used concentrations of 5 and $10 \mathrm{wt} \%$ of OMMT in order to investigate the effect of nanoparticles in a relatively large composition range. These results will be published in a forthcoming paper. ${ }^{29}$ To the best of our knowledge, very little information is available on studies relevant to the mechanical properties of clay-filled PHB composites prepared in the melt state ${ }^{50}$ For other polymeric matrices, biodegradable or not, the best improvements of mechanical properties are usually found for clay loadings from 3 to 5-10 wt \%. For higher OMMT loadings, the mechanical properties of the composites tend to decrease again. ${ }^{9,51}$ In addition, the density of OMMT is higher than that of PHB (1.5 vs $1.2 \mathrm{t} / \mathrm{m}^{3}$ ), so an increase in the loading of OMMT would also lead to a higher density of the composites. This is an undesired effect, because it would decrease the MI of the composite and hence lead to large material requirements. Therefore, the clay content should be kept as low as possible. Concluding further, a practicable way of increasing the mechanical properties and hence also the MI value could be the use of a compatibilizer, like maleated PHB. ${ }^{52}$

On the contrary, in natural fibers-filled composites it is possible to obtain improvements in the modulus up to a concentration of $30-40 \%$ in the weight of filler. ${ }^{53}$ Furthermore, the density of SCB is very low $\left(0.7 \mathrm{t} / \mathrm{m}^{3}\right)$ if compared with PHB or OMMT. So, increasing the fibers' concentration can theoretically lead to the preparation of new PHB-SCB composites with superior Young modulus, decreasing at the same 
time the density of the composite. On the other hand, the decrease of the percentage of PHB in the composite can also represent a drawback: the production of natural fibers requires only little energy, but the production of PHB, if made from sugar cane, can even be a net source of NREU. Further investigations about this topic, concerning the preparation of new composites with different formulations, are still in progress.

\section{Conclusions}

A comparative LCA has been performed in order to evaluate the possible environmental benefits connected to the replacement conventional petrochemical plastics with PHB-based composites prepared with a melt-mixing technique. Sugar cane bagasse and organophilic montmorillonite have been used as PHB fillers. A conventional high-impact polystyrene CRT monitor housing and glass-fibers-filled polypropylene internal panels of an average car have been chosen as reference products. Nonrenewable energy use and global warming potential over a 100 years time horizon have been selected as environmental indicators.

The relatively low Young modulus and high density for PHBbased composites compared to conventional plastics are a disadvantage for their environmental performance, but substantial environmental benefits can be anyway obtained thanks to the saving inputs in the PHB production process. On a cradleto-factory gate basis, all PHB composites appear to be environmentally superior to conventional polymers used for the two chosen applications. When the analysis is extended to the system cradle-to-grave (including the use phase and with post-consumer waste incineration with energy recovery), PHB composites score still better only for CRT monitor housing. In the case of automotive application, the weight of the functional unit becomes overriding, and no substantial savings were observed for both NREU and GWP100. Finally, regardless of the system boundaries, $\mathrm{PHB}-\mathrm{SCB}$ composites show lower impact values than $\mathrm{PHB}-\mathrm{OMMT}$, and natural fibers seem the most promising filler in order to further improve the environmental performances of PHB composites.

Acknowledgment. This study has been performed with the framework of the EU-funded Network of Excellence NANOFUN-POLY "Nanostructured and Functional Polymer-based Materials and Nanocomposites". The partial financial support by PRIN 2004 prot. 2004035937 is also acknowledged. The authors wish to thank Dr. Elizabeth Grillo Fernandes and Mr. Cristiano Tramidi of the Department of Chemistry and Industrial Chemistry of the University of Pisa for their essential help in preparation and characterization of $\mathrm{PHB}-\mathrm{OMMT}$ composites.

\section{References and Notes}

(1) Heyde, M. Polym. Degrad. Stab. 1998, 59, 3.

(2) Kim, S.; Dale, B. E. Int. J. LCA 2005, 10, 200

(3) Vink, E. T. H.; Rábago, K. R.; Glassner, D. A.; Gruber, P. R. Polym. Degrad. Stab. 2003, 80, 403 .

(4) Gerngross, T. U. Nat. Biotech. 1999, 17, 541.

(5) Akiyama, M.; Tsuge, T.; Doi, Y. Polym. Degrad. Stab. 2003, 80, 183.

(6) Fernandes, E. G.; Pietrini, M.; Chiellini, E. Macromol. Symp. 2004, $218,157$.

(7) Ha, C. S.; Cho, W. J. Prog. Polym. Sci. 2002, 27, 759.

(8) Okamoto, M. J. Ind. Eng. Chem. 2004, 10/7, 1156.

(9) Sinha Ray, S.; Bousmina, M. Prog. Polym. Sci. 2005, 5, 962.

(10) Sinha Ray, S.; Yamada, K.; Okamoto, M.; Ueda, K. Polymer 2003, $44,857$.

(11) Choi, W. M.; Kim, T. W.; Park, O. O., Chang, Y. K.; Lee, J.W. J. Appl. Polym. Sci. 2003, 90. 525.

(12) Wollerdorfer, M.; Bader, H. Ind. Crop. Prod. 1998, 8, 112.
(13) Fernandes, E. G.; Pietrini, M.; Chiellini, E. Biomacromolecules 2004, 5,1205 .

(14) Lloyd, S. M.; Lave, L. B. Environ. Sci. Technol. 2003, 37, 3458.

(15) Wötzel, K.; Wirth, R.; Flake, M. Angew. Makromol. Chem. 1999, 272,121

(16) Schmidt, W. P.; Beyer H. M. Proceedings of the Third SAE conference on Total Life Cycle, 1998, Graz, 251.

(17) Diener, J.; Siehler, U. Angew. Makromol. Chem. 1999, 272, 1.

(18) Corbière-Nicollier, T.; Gfeller Laban, B.; Lundquist, L.; Leterrier, Y.; Månson, J. A. E.; Jolliet, O. Res. Cons. Recycl. 2001, 33, 267.

(19) International Organization for Standardization (ISO): Geneva, 1997.

(20) Baumann, H.; Tillman, A. M. The Hitch Hiker's Guide to LCA; Studentlitteratur AB: Lund, 2004.

(21) Huijbregts, M. A. J.; Rombouts, L. J. A.; Hellweg, S.; Frischknecht, R.; Hendriks, A. J.; Van de Meent, D.; Ragas, A. M. J.; Reijnders, L.; Struijss, J. Environ. Sci. Technol. 2006, 40, 641.

(22) Personal communication with Dr. Ortega, S. PHB Industrial SA, Serrana SP, Brazil.

(23) ADM and Metabolix Announce First Commercial Plant for PHA Natural Plastics; Metabolix, Inc., Cambridge MA, 2006. http:// www.metabolix.com/publications/pressreleases/PR20060213.html.

(24) Frischknecht, R.; Faist Emmenegger, M. Strommix und Stromnetz in Sachbilanzen von Energiesystemen: Grundlagen für den ökologischen Vergleich von Energiesystemen und den Einbezug von Energiesystemen in Ökobilanzen für die Schweiz; Final report ecoinvent 2000 No. 6; Paul Scherrer Institut Villigen, Swiss Centre for Life Cycle Inventories, Duebendorf, 2003

(25) Leet Socolof, M.; Overly, G. J.; Kincaid, L. E.; Geibig, J. R. Desktop Computer Displays: A Life-Cycle Asessemnt Volume 1; Center for Clean Products and Clean Technologies, University of Tennessee, Knoxville, 2001. http://www.epa.gov/dfe/pubs/comp-dic/lca/index.htm.

(26) A Material of Choice for the Automotive Industry; PlasticsEurope, Brussels, 1999. http://www.plasticseurope.org/Content/Default.asp?pageid $=89$.

(27) Chiellini, E.; Fernandes, E. G.; Pietrini, M.; Solaro, R. Macromol. Symp. 2003, 197, 45.

(28) Fernandes, E. G.; Pietrini, M.; Chiellini, E. Manuscript in preparation.

(29) Fernandes, E. G.; Tramidi, C.; Chiellini, E. Manuscript in preparation.

(30) MatWeb-Material Property Data. http://www.matweb.com/index.as$\mathrm{p}$ ? ckck $=1$.

(31) Ashby, M. F. Materials selection in Mechanical Design, 3rd ed; Elsevier Butterworth-Heinemann: Burlington, 2005.

(32) Roes, L.; Marsili, E.; Nieuwlaar, E.; Patel, M. Manuscript in preparation

(33) Patel, M.; Crank, M., Dornburg, V.; Hermann, B.; Roes, L.; Hysing, B.; Overbeek, van, L.; Terragni, F.; Recchia, E. Medium and LongTerm Opportunities and Risks of the Biotechnological Production of Bulk Chemicals from Renewable Resources-The BREW Project; Prepared Under the European Commission's GROWTH Programme (DG Research), 2006, http://www.chem.uu.nl/brew/.

(34) Phylipsen, D.; Kerssemeeckers, M.; Blok, K.; Patel, M.; de Beer, J. Clean Technologies in the Materials Sector-Current and Future Environmental Performance of Material Technologies; Report Commissioned by European Commission's Institute for Prospective Technological Studies (IPTS), Ecofys, Department of Science, Technology and Society, Utrecht University, Utrecht, 2002.

(35) Jungbluth, N. Glass Fibre Reinforced Plastic Products in Life Cycle Inventories of Building Products; Final Report Ecoinvent 2000 No. 7; EMPA Duebendorf, Swiss Centre for Life Cycle Inventories, Duebendorf, 2003.

(36) Macedo, I. C.; Leal, M. R. L. V.; da Silva J. E. A. R. Assessment of Greenhouse Gas Emissions in the Production and Use of Fuel Ethanol in Brazil; Nucleo Interdisciplinar de Planejamento Energetico da Universitade Estadual de Campinas, Campinas, and Centro de Tecnologia Copersucar, Piracicaba, 2004. http://www.unica.com.br/ i_pages/files/gee3.pdf.

(37) Boustead, I. Eco-Profiles of the European Plastics Industry: Polypropylene (PP); PlasticsEurope, Brussels, 2005. http://www.plasticseurope.org/content/default.asp?PageID=392\#.

(38) Boustead, I. Eco-Profiles of the European Plastics Industry: Polystyrene (High Impact) (PS); PlasticsEurope, Brussels, 2005. http:// www.plasticseurope.org/content/default.asp?PageID=392\#.

(39) Boustead, I. Eco-Profiles of the European Plastics Industry: Polypropylene Injection Molding; PlasticsEurope, Brussels, 2005. http:// www.plasticseurope.org/content/default.asp?PageID=392\#.

(40) Spielmann, M.; Kagi, T.; Stadler, P.; Tietje, O. Life Cycle Inventories of Transport Services; Final Report Ecoinvent 2004 No. 14; Swiss Centre for Life Cycle Inventories, Duebendorf, 2004. 
(41) Gutowski, T.; Dahmus, J.; Thiriez, A. 13th CIRP International Conference on Life Cycle Engineering, 2006, Leuven.

(42) Joosten, L. A. J. Process Data Description for the Production of Synthetic Organic Materials Department of Science, Technology and Society, Utrecht University, The Netherlands, 1998.

(43) Kalligeros, S.; Zannikos, F.; Stournas, S.; Lois, E.; Anastopoulos, G. Int. J. Energy Res. 2001, 25, 1381

(44) Lee, S. Y. Biotechnol. Bioeng. 1996, 49, 1.

(45) Hänggi, U. J. FEMS Microbiol. Rev. 1995, 16, 213.

(46) Zhang, J.; McCarthy, S.; Whitehouse, R. J. Appl. Polym. Sci. 2004, 94, 483

(47) Bucci, D. Z.; Tavares, L. B. B.; Sell, I. Polym. Test. 2005, 24, 564
(48) Joshi, S. V.; Drzal, L. T.; Mohanty, A. K.; Arora, S. Compos.: Part A 2004, 35, 371.

(49) Avella, M.; La Rota, G.; Martuscelli, E.; Raimo, M.; Sadocco, P.; Elegir, G.; Riva, R. J. Mater. Sci. 2000, 35, 829.

(50) Maiti, P.; Batt, C. A.; Giannellis, E. P. Polym. Mater. Sci. Eng. 2003 $88,58$.

(51) Sinha Ray, S.; Okamoto, M. Prog. Polym. Sci. 2003, 28, 1539.

(52) Chen, C.; Peng, S.; Fei, B.; Zhuang, Y.; Dong, L.; Feng, Z.; Chen, S.; Xia, H. J. Appl. Polym. Sci. 2003, 88, 659.

(53) Bledzki, A. K.; Gassan, J. Prog. Polym. Sci. 1999, 24, 221.

BM0700892 